\title{
Technical Note: Using DEG-CPCs at upper tropospheric temperatures
}

\author{
D. Wimmer ${ }^{1,2}$, K. Lehtipalo ${ }^{2,3}$, T. Nieminen ${ }^{2,4}$, J. Duplissy ${ }^{2,4}$, S. Ehrhart ${ }^{1,5}$, J. Almeida ${ }^{1,5}$, L. Rondo ${ }^{1}$, A. Franchin ${ }^{2}$, \\ F. Kreissl ${ }^{1}$, F. Bianchi ${ }^{6,7}$, H. E. Manninen ${ }^{2}$, M. Kulmala ${ }^{2}$, J. Curtius ${ }^{1}$, and T. Petäjä ${ }^{2}$ \\ ${ }^{1}$ Institute for Atmospheric and Environmental Sciences, Goethe-University of Frankfurt, \\ 60438 Frankfurt am Main, Germany \\ ${ }^{2}$ Department of Physics, University of Helsinki, 00014 Helsinki, Finland \\ ${ }^{3}$ Airmodus Ltd, Helsinki, Finland \\ ${ }^{4}$ Helsinki Institute of Physics, 00014, Helsinki, Finland \\ ${ }^{5}$ CERN, 1211 Geneva, Switzerland \\ ${ }^{6}$ Laboratory for Atmospheric Chemistry, Paul Scherrer Institute, 5232 Villigen, Switzerland \\ ${ }^{7}$ Institute for Atmospheric and Climate Science, ETH Zürich, 8092 Zürich, Switzerland
}

Correspondence to: D. Wimmer (daniela.wimmer@helsinki.fi)

Received: 21 March 2014 - Published in Atmos. Chem. Phys. Discuss.: 20 May 2014

Revised: 22 May 2015 - Accepted: 14 June 2015 - Published: 13 July 2015

\begin{abstract}
Over the last few years, several condensation particle counters (CPCs) capable of measuring in the sub- $3 \mathrm{~nm}$ size range have been developed. Here we study the performance of CPCs based on diethylene glycol (DEG) at different temperatures during Cosmics Leaving OUtdoor Droplets (CLOUD) measurements at CERN. The data shown here are the first set of verification measurements for sub- $3 \mathrm{~nm}$ CPCs under upper tropospheric temperatures using atmospherically relevant aerosol particles. To put the results in perspective we calibrated the DEG-CPC at room temperature, resulting in a cut-off diameter of $1.4 \mathrm{~nm}$. All diameters refer to mobility equivalent diameters in this paper. At upper tropospheric temperatures ranging from $246.15 \mathrm{~K}$ to $207.15 \mathrm{~K}$, we found cut-off sizes relative to a particle size magnifier in the range of 2.5 to $2.8 \mathrm{~nm}$. Due to low number concentration after size classification, the cut-off diameters have a high uncertainty $( \pm 0.3 \mathrm{~nm})$ associated with them. Operating two laminar flow DEG-CPCs with different cut-off sizes together with other aerosol instruments, we looked at the growth rates of aerosol population in the CLOUD chamber for particles smaller than $10 \mathrm{~nm}$ at different temperatures. A more consistent picture emerged when we normalized the growth rates to a fixed gas-phase sulfuric acid concentration. All of the instruments detected larger growth rates at lower temperatures, and the observed growth rates decreased
\end{abstract}

as a function of temperature, showing a similar trend for all instruments. The theoretical calculations had a similar but much smaller temperature dependency.

\section{Introduction}

Condensation particle counters (CPCs) measure the total number concentration of aerosol particles by activating and growing them with a supersaturated vapour. Once the particles are grown they are counted optically with a laser (McMurry, 2000). CPCs provide information about the total particle concentration above a certain size. The parameter used to describe the performance of a CPC is the cut-off diameter, which is defined as the diameter at which the particles are counted with $50 \%$ efficiency. By using several CPCs with different cut-off diameters, additional information such as the growth rates can be retrieved (Riipinen et al., 2007; Riccobono et al., 2012; Lehtipalo et al., 2014). In this paper all diameters refer to mobility equivalent diameters (Mäkelä et al., 1996). CPCs capable of measuring reliably in the size range below $3 \mathrm{~nm}$ have been developed only recently (Kuang et al., 2012a, b; Vanhanen et al., 2011; Sipilä et al., 2009). The work presented here focuses on ultrafine CPCs using diethylene glycol (DEG) as condensing liquid, which has 
been tested in a study by Iida et al. (2009) and proven to be suited for activation of sub- $3 \mathrm{~nm}$ aerosol particles. CPCs are widely used for ground-based measurements, but they are also deployed during airborne measurements (Crumeyrolle et al., 2010; O'Dowd et al., 1998; Schobesberger et al., 2013), where ambient conditions, such as temperature and pressure, are changing. It has been shown (Kulmala et al., 2007; Wimmer et al., 2013; Kangasluoma et al., 2014) that the counting efficiency curves of the sub- $3 \mathrm{~nm}$ CPCs change according to the particle composition. As the working principle of laminar flow CPCs is based on creating supersaturation and activation by creating a temperature difference, their performance might depend also on the ambient temperature. One issue with CPCs measuring at low temperatures is whether the particles evaporate during the transition from the cold measurement environment to the warmer CPC. Another issue is whether the temperature profile (and thus supersaturation) inside the instrument changes when cold sample air is brought in, possibly resulting in a cut-off shift.

At CLOUD5, which took place in autumn 2011 at CERN, measurements were performed to study nucleation under upper tropospheric temperatures. The potential influence of the ambient temperature on the detection efficiency of the CPC used for determining the nucleation rates at $2 \mathrm{~nm}$ was investigated. It has been shown that growth rates can be size dependent (Kulmala et al., 2013; Nieminen et al., 2010), especially in the smaller sizes, resulting in a need to determine them reliably. Growth rates were determined at $2 \mathrm{~nm}$ using different instruments. The comparison with an ion spectrometer gives important additional information as the effects of the sample air temperature on the particle detection method, such as volumetric flow rate and mobility to diameter conversion, can be accounted for.

The aim of this study is to investigate the possibility for using CPCs at temperatures which can be encountered in the upper troposphere (UT; e.g. during flight measurements). Note that the experiments presented here were carried out at ambient pressure plus 4-5 mbar overpressure. Therefore, influences of operating the CPCs at UT pressures on the cut-offs and other performance characteristics of the CPCs were not investigated in our study. The chamber is operated at this slight overpressure to avoid accidental contamination. We studied how the counting efficiency curve of a laminar flow DEG-CPC changes when varying the temperature and how the sub-3 $\mathrm{nm}$ growth rates behave at low temperatures by using different instruments.

\section{The CLOUD facility}

The CLOUD experiment was designed to study nucleation in a controlled environment under well-defined conditions, such as trace gas composition, relative humidity and temperature. (Duplissy et al., 2010; Kirkby et al., 2011). In the design, great care was taken to ensure high cleanliness, as it has been shown that impurities of trace gases (already at concentrations as low as few $\mathrm{ppt}_{v}$ ) such as $\mathrm{NH}_{3}$ influence the nucleation rates (Ball et al., 1999; Kirkby et al., 2011; Schobesberger et al., 2013). The chamber as well as all the gas lines and connections to the chamber are made of stainless steel. The CLOUD facility comprises a $26.1 \mathrm{~m}^{3}$ cylindrical stainless steel chamber equipped with a fibre optic UV system (Kupc et al., 2011). It includes a very stable temperature control unit $( \pm 0.01 \mathrm{~K})$ with a temperature range from $203.15 \mathrm{~K}$ up to $373.15 \mathrm{~K}$. Two mixing fans are installed in the upper and lower part of the chamber to ensure homogenous internal mixing (Voigtländer et al., 2012). Measurements can be performed under high ion pair production rates (pion beam from CERN Proton Synchrotron on, clearing field grounded), natural level of ion production rates (beam off, clearing field grounded) and completely neutral conditions (beam off, clearing field on). The clearing field is created by applying $\pm 30 \mathrm{kV}$ to two circular grids at the top and the bottom of the chamber, removing the small ions, which are continuously generated by the galactic cosmic rays, in less than $1 \mathrm{~s}$. The nucleation measurements in the CLOUD5 campaign, which took place in autumn 2011, were mainly performed at three different temperature ranges: [206-208], [221-223] and [245-248] K. To compare the performance of the chamber and the instruments to previous experiments, measurements at $278.15 \mathrm{~K}$ were also performed. In CLOUD the instruments draw air from sampling lines with a length of $75 \mathrm{~cm}$ and an outer diameter of $1 / 2$ or 1 inch depending on the required sample flow rate. The chamber is operated under overpressure of 4-5 mbar. Under-pressure is to be avoided, as ambient air, DEG or butanol vapours from the instruments could leak back into the chamber, for example during a pump failure.To guarantee the same temperature in the chamber and in the sampling lines, the sampling lines were thermally coupled to the chamber using copper. To avoid thermal exchange with the room air, the sampling lines were wrapped with thermal insulation material on top of the copper wires.

For the measurements analyzed in this study, the particles formed in the CLOUD chamber consisted mainly of sulfuric acid and water. A chemical ionization mass spectrometer (CIMS, Kürten et al., 2011) was used for measuring the gaseous sulfuric acid (SA) concentration. The sub-5 nm CPCs used for measuring the total particle concentrations and calculating nucleation and growth rates were a particle size magnifier (PSM; Airmodus A09), a butanol-based laminar flow CPC (3776; TSI Inc.) and two DEG-based laminar flow CPCs. Details about the setup and performance of the DEG-CPCs can be found in Wimmer et al. (2013). In short, the DEG-CPC 1 was set to a saturator temperature of $325 \mathrm{~K}$ and an inlet flow rate of $1.5 \mathrm{~L} \mathrm{~min}^{-1}$, whereas the DEG-CPC 2 has a saturator temperature of $328 \mathrm{~K}$ and an inlet flow rate of $1.8 \mathrm{~L} \mathrm{~min}^{-1}$. The condenser temperatures are $283 \mathrm{~K}$ in both cases. It should be noted that the differential mobility analyzer (DMA) that was used for size selecting the particles for the calibration measurements shown here was a 
commercial nano-DMA (Grimm Aerosol Technik, S-DMA, 55-100), whereas for the calibration measurements at room temperature, a high-resolution DMA (Herrmann et al., 2000) was used, resulting in a better size resolution for those measurements. A comparison of the performance of the different DMAs can be found in Jiang et al. (2011b).

\section{Calibrating CPCs using the CLOUD chamber as an aerosol source}

The calibration unit consisted of the CLOUD chamber as the particle source. Doing so, the calibration particle composition was exactly the same as during the nucleation experiments. The particle production was triggered by switching on the UV lamp after adding $\mathrm{SO}_{2}, \mathrm{O}_{3}$ and water vapour to the chamber. The particles were sampled from a core sampling probe, which was used to minimize diffusion losses. The core sampling probe consisted of a coaxial tube with a conical tip and an outer diameter of $6 \mathrm{~mm}$. A fraction of the flow was sampled through that tube from the centre of the flow, whereas the flow closer to the walls of the main tube was discarded. No external charger was used; only the naturally negatively charged fraction of particles which were size selected with a nano-DMA (Grimm Aerosol Technik, S-DMA, 55-100) were used for the calibration. The laminar flow DEG-CPC 1 was calibrated according to the setup shown in Fig. 1. To measure the total concentration after the DMA, as a first test, a Faraday cup electrometer was used as a reference. The particle concentrations after the size selection were low due to many factors, including low ion concentrations (about $400 \mathrm{~cm}^{-3}$ ) (Kirkby et al., 2011), fast particle growth (i.e. particles grow out of the desired size range quickly) and internal losses in the DMA. This resulted in an unacceptably high signal-to-noise ratio and therefore it was decided to use a PSM at a fixed cut size as the reference instrument instead of an electrometer. The PSM has a significantly lower cut-off size than the laminar flow DEG-CPC, a steep counting efficiency curve $\left(d_{50}=1.1 \mathrm{~nm}, d_{90}=1.5 \mathrm{~nm}\right.$ for ammonium sulfate, Wimmer et al., 2013), and it is a single particle counter. We assume that the PSM behaves similarly to the laminar flow DEG-CPC regarding the ambient temperature. To ensure that the cut-off diameter of the PSM stays the same despite varying experimental temperatures, the saturator temperature of the PSM was adjusted for each temperature in the CLOUD chamber. By keeping the homogeneous background in the PSM constant, the assumption is made that the supersaturation within the instrument stays consistent. More detailed discussion about the influence of the temperature settings on the instrument behaviour when using an ultrafine DEG-based CPC can be found in e.g. Jiang et al. (2011a) and Kangasluoma et al. (2015). These assumptions have not been quantified and certainly add some uncertainty to the results. It would be highly interesting to investigate the effect of the ambient temperature on ultrafine

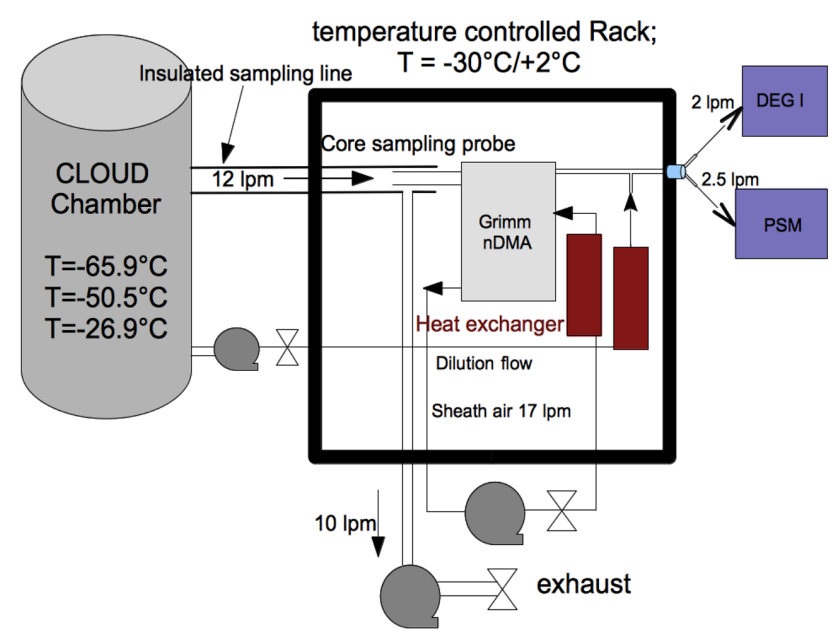

Figure 1. Sketch of the calibration setup. The calibration unit was in a temperature-controlled rack, while the CPCs were at room temperature. The temperature inside the rack was $245.15 \mathrm{~K}$ for the measurements at lower temperatures, whereas the rack temperature was $275.15 \mathrm{~K}$ for the measurements at $246.25 \mathrm{~K}$ in the chamber. To minimize diffusion losses, a core sampling probe was used from the chamber to the calibration system. The CLOUD chamber was used to produce naturally charged particles. A nano-DMA was used to size select the particles and as reference a PSM, with a significantly lower cut-off $(1.1 \mathrm{~nm})$ than the calibrated CPC. The sheath air of the DMA and the dilution flow after the DMA went through a heat exchanger, consisting of copper tubing to ensure the same temperature for all flows.

CPCs further, but this is not in the scope of this technical note. With this setup, the problem with a too low signal-tonoise ratio could be reduced; in frame of the measurements presented here, these were the best results we could achieve.

During the calibration measurements, the nano-DMA was set to stepping mode, resulting in better statistics for each size bin. The size range of the nano-DMA was limited to a maximum size of $10 \mathrm{~nm}$, which requires keeping the particles in that size range for the time period of each calibration experiment. Slow enough growth was achieved by periodically switching on and and off UV lights at very low intensities for a few minutes. As soon as the particles grew to sizes bigger than $10 \mathrm{~nm}$, the UV was switched on again to trigger new formation and growth of small particles. To ensure stable temperature of the calibration system, the DMA was located in a temperature-controlled rack, which was kept at $243.15 \mathrm{~K}$ for the measurements at $207.25 \mathrm{~K}$ and $222.65 \mathrm{~K}$ in the chamber, whereas the rack was at $275.15 \mathrm{~K}$ for the measurements at $246.25 \mathrm{~K}$ in the chamber. Due to technical limitations of the temperature control of the racks and the heat load of the instruments inside the racks, it was impossible to reach the same temperature as in the chamber. For the inlet system to the DMA, a core sampling line was used to lower diffusion losses. The transport flow for the DMA was set to $10 \mathrm{~L} \mathrm{~min}^{-1}$, while the aerosol flow through the DMA 


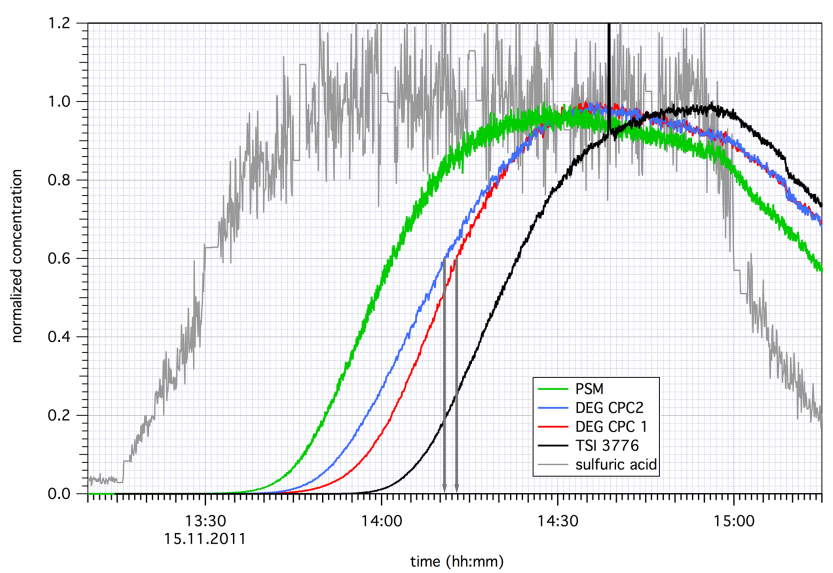

Figure 2. Example of a nucleation experiment during CLOUD5. The temperature inside the chamber in the shown example was $223.15 \mathrm{~K}$ and the clearing field was at high voltage, meaning it was a neutral run. The red, blue, green and black curves show the normalized concentrations for the DEG-CPCs, PSM and TSI 3776 CPC respectively. The grey line shows the normalized sulfuric acid concentration measured by the CIMS. The growth rates are calculated by finding time difference at half maximum between the two DEGCPCs, assuming a difference in diameter of $0.3 \mathrm{~nm}$.

was $2 \mathrm{~L} \mathrm{~min}^{-1}$. The sheath flow of the DMA passed through a heat exchanger. The dilution flow after the DMA was taken from a different sampling line to guarantee the same composition and temperature of the stream. By setting the sheath flow to $17 \mathrm{~L} \mathrm{~min}^{-1}$, a good sheath air to sample flow rate ratio was achieved to ensure a narrow size distribution in the DMA (Jiang et al., 2011a).

\section{Method for determining growth rates from the DEG-CPCs}

The low cut-off CPCs (DEG-CPCs and PSMs) have been used at CLOUD to determine the initial growth rate (GR) of the particles. This is relevant e.g. for scaling the nucleation rates, measured at larger sizes (Kirkby et al., 2011; Almeida et al., 2013; Kulmala et al., 2013) down to smaller sizes (e.g. $1.7 \mathrm{~nm}$ ) (Kerminen and Kulmala, 2002). To determine whether the shift in the cut-off curves influences the scientific outcome of the measurements with the laminar flow DEG-CPCs significantly, the growth rates have been determined and compared to other instruments (NAIS (Mirme and Mirme, 2013) and PSM). The growth rates from the PSM were determined by using two PSMs at different cut sizes together with the other ultrafine CPCs, according to the method shown in Lehtipalo et al. (2014). From the NAIS the growth rates were determined by following the time evolution of the maximum concentration in each size bin of the instrument (Kulmala et al., 2012).

An example that illustrates the chosen method for calculating the growth rates is shown in Fig. 2. The raw signal from the CPCs was smoothed using a running average of $5 \mathrm{~s}$. The total measured number concentration was normalized to the maximum for each run separately. Next, the times when the concentrations reached half of the maximum concentrations were determined. The half maximum is defined by the range between 50 and $60 \%$ of the maximum concentration as even the averaged data show fluctuations. The time difference between the half maxima of the two DEG-CPCs was then used for determining the growth rates. A similar method for establishing GRs from CPCs with different cut-off sizes is described in Riccobono et al. (2012) and Lehtipalo et al. (2014). The cut size of the DEG-CPC 2 could not be determined via calibration measurements using the CLOUD chamber. The cut-off diameter was estimated to be $0.3 \mathrm{~nm}$ smaller than the DEG-CPC 1, based on the growth rates calculated using different ultrafine CPCs and their respective cut-off diameters $\left(\right.$ PSM $d_{50}=1.1 \mathrm{~nm}$, TSI $\left.3776 d_{50}=2.9 \mathrm{~nm}\right)$.

The times used for the growth rate analysis are marked with arrows in Fig. 2. The half maximum points $(60 \%$ in this case, which was the allowed range due to statistics) here were reached at 14:10:45 and 14:12:50, resulting in a time difference of $125 \mathrm{~s}$ and therefore in a GR of $9.3 \mathrm{nmh}^{-1}$. The temperature in the chamber in this case was $223.15 \mathrm{~K}$ and the electrodes of the high voltage control were set to $\pm 30 \mathrm{kV}$, so it was a neutral run.

The nucleation experiments in CLOUD which were used for the GR calculations shown here were done at different temperatures and sulfuric acid concentrations. To determine a possible temperature trend for the different instruments, the growth rates shown here were normalized to the same sulfuric acid concentration $\left(10^{7} \mathrm{~cm}^{-3}\right)$. This was done by multiplying the calculated growth rates, which are a function of the sulfuric acid concentration with $10^{7}$. This factor was then divided by the measured sulfuric acid concentration. That procedure was applied for each growth rate/SA concentration pair individually (see Eq. 1). This is a very simplified method based on the assumption that there is a linear relationship between the growth rates and the sulfuric acid concentration. From the measurements with a high-resolution mass spectrometer, it is known that at temperatures below $278 \mathrm{~K}$ the major species contributing to the nucleation and growth in the CLOUD chamber is sulfuric acid (Schobesberger et al., 2013). The normalization was done using the following equation:

$\mathrm{GR}_{\text {norm }}=\mathrm{GR}_{\text {calc }}\left(\mathrm{H}_{2} \mathrm{SO}_{4}\right) \times 10^{7} / \mathrm{H}_{2} \mathrm{SO}_{4 \text { meas }}$.

$\mathrm{GR}_{\text {calc }}$ here means the GRs calculated from the CPC measurements and $\mathrm{H}_{2} \mathrm{SO}_{4}$ meas means the measured sulfuric acid concentration from the CIMS. Growth rates higher than $20 \mathrm{nmh}^{-1}$ have been neglected, as then the time difference between the two laminar flow DEG-CPCs becomes too small. 


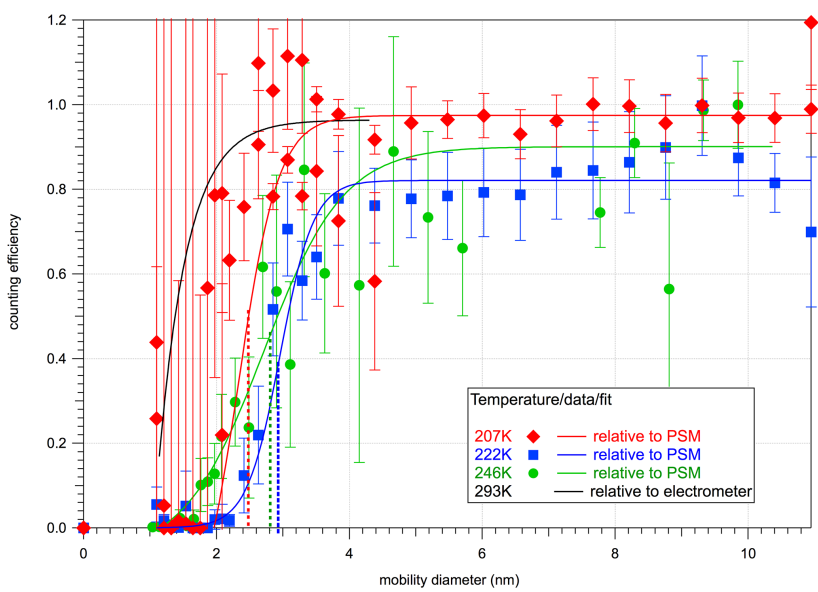

Figure 3. Results from calibration measurements. The blue, green and red curves show fits to the results from calibration measurements for the DEG-CPC 1, done at CLOUD in autumn 2011 and the symbols show the measured data points at three different temperatures $(246.25,222.65,207.15 \mathrm{~K})$. Black curve shows laboratory calibrations (Wimmer et al., 2013) using negatively charged ammonium sulfate clusters. The $d_{50}$ relative is shifted from about $1.4 \mathrm{~nm}$ at room temperature (relative to an electrometer) to $2.5 \mathrm{~nm}$ in the case of $207.15 \mathrm{~K}$ about $2.6 \mathrm{~nm}$ for $246.25 \mathrm{~K}$, and for the $222.65 \mathrm{~K}$ the cut-off is shifted to $2.8 \mathrm{~nm}$. To illustrate the values for the cutoffs, dashed lines pointing to the according sizes are added to the figure. Due to low statistics, the $y$ axis error bars are rather large. The error, resulting from the finite width of the transfer function of the nano-DMA used for the low temperature calibration measurements, is 0.185 at $1.47 \mathrm{~nm}, 0.158$ at $1.78 \mathrm{~nm}$ and 0.14 at $3 \mathrm{~nm}$ according to Jiang et al. (2011b).

\section{Results}

\subsection{Upper tropospheric temperature calibration results}

Figure 3 shows the calibration curves at different temperatures $(207.25,222.65,246.25,293 \mathrm{~K})$. Due to the huge scatter and large error bars a number of the red data points seem to indicate a small cut-off at $208.15 \mathrm{~K}$, but the majority of the data points below $2 \mathrm{~nm}$ are at 0 and the fit shows that the cut-off relative to a PSM is shifted. The data points in Fig. 3 are taken from the experiments with the highest particle concentrations after the DMA. Three-parameter sigmoidal fits (Stolzenburg and McMurry, 1991) are applied to the measured data points

$\operatorname{fit}\left(d_{p}\right)=a+b /\left(1+\exp \left(-c \cdot\left(d_{p}-d_{50}\right)\right)\right.$

and are weighted based on the error bars of the measured data points. To fit the $207.25 \mathrm{~K}$ data, the parameter $c$ (= rate of change in $1 / \mathrm{nm}$ ) had to be fixed to 0.3 and the base value (parameter $a$ ) to 0 ; otherwise the fit would not have converged due to the large error bars in the smaller sizes. The values for the half maxima $\left(=d_{50}\right)$ given by the fits are $2.5 \pm 0.05$ for the data points at $207.25 \mathrm{~K},(2.6 \pm 0.1) \mathrm{nm}$ for $246.25 \mathrm{~K}$ and
$(2.8 \pm 0.05) \mathrm{nm}$ for the data taken at $222.65 \mathrm{~K}$. As the overall particle concentration after the DMA was typically $10 \mathrm{~cm}^{-3}$, the relative errors of the measurements are large. This means that the results are qualitative. Time and technical limitations prevented the acquisition of more data.

Nevertheless there is a clear shift in the cut-off diameter relative to a PSM, towards larger sizes at lower temperatures. Analysis using CLOUD5 run data at higher temperatures for determining the cut-offs of the DEG-CPCs at room temperature $(295 \mathrm{~K})$ showed comparable results to the laboratory calibration measurements $\left(d_{50} \sim 1 \mathrm{~nm}\right)$. The shift in the cutoff size from room temperature to UT temperatures could be caused by shifts in the internal temperature-dependent diffusion losses. The calculation (Baron and Willeke, 2001) shows that this difference is negligible. At $246.25 \mathrm{~K}$, the diffusion loss corrected $d_{50}$ is at $2.7 \mathrm{~nm}$, whereas it is $2.8 \mathrm{~nm}$ for the uncorrected data. It is worth noting here that the temperaturecontrolled rack was set to the same temperature $(243 \mathrm{~K})$ for the calibration measurements at 207 and $222 \mathrm{~K}$. The calibrations at a chamber temperature of $246.25 \mathrm{~K}$ were done with a rack temperature of $275 \mathrm{~K}$, which is much closer to the chamber temperature.

Two effects could cause the shift in the counting efficiency curves. The first one is a possible change in the profile of supersaturation in the condenser of the CPC due to a different temperature of the sample flow. In that case, the shift would be expected to be a function of temperature. Modelling results using COMSOL 5.0 multiphysics model show that, assuming a constant flow of $0.3 \mathrm{~L} \mathrm{~min}^{-1}$ from the inlet of the CPC until the beginning of the capillary, the final temperature of the flow is $326 \mathrm{~K}$ for an inlet temperature of $208.15 \mathrm{~K}$ and the same for an inlet temperature of $298.15 \mathrm{~K}$. The dimensions that were used for the modelling are $2.2 \mathrm{~cm}$ inlet at ambient temperature; $17.3 \mathrm{~cm}$ inside the CPC cabin, assuming a temperature of $303.15 \mathrm{~K}$; and $2.7 \mathrm{~cm}$ inside the saturated region, assuming a temperature of $328.15 \mathrm{~K}$. These results suggest that the ambient temperature does not influence the profile of the saturation ratio in the condenser of the CPC. The second effect would be that the shift is caused by evaporation of particles before being activated in the CPC. This means that after the particles are size selected in the DMA, which is still in the cold environment, they shrink. That leads to a shift in the counting efficiency as the particles changed in size after they were size selected.

\subsection{Comparison of growth rates}

Figure 4 shows the growth rates normalized to a $\mathrm{H}_{2} \mathrm{SO}_{4}$ concentration of $10^{7} \mathrm{~cm}^{-3}$ (Eq. 1) in $\mathrm{nm} \mathrm{h}^{-1}$ on the $y$ axis as a function of temperature for the laminar flow DEG-CPCs, the PSMs and the NAIS. All the GRs are determined at about $2 \mathrm{~nm}$. The normalized GRs are averaged for the different temperature ranges [206-208] K, [221-223] K and [245-248] K and also the temperatures are averaged for each range. The error bars show the standard deviation of the averages of the 


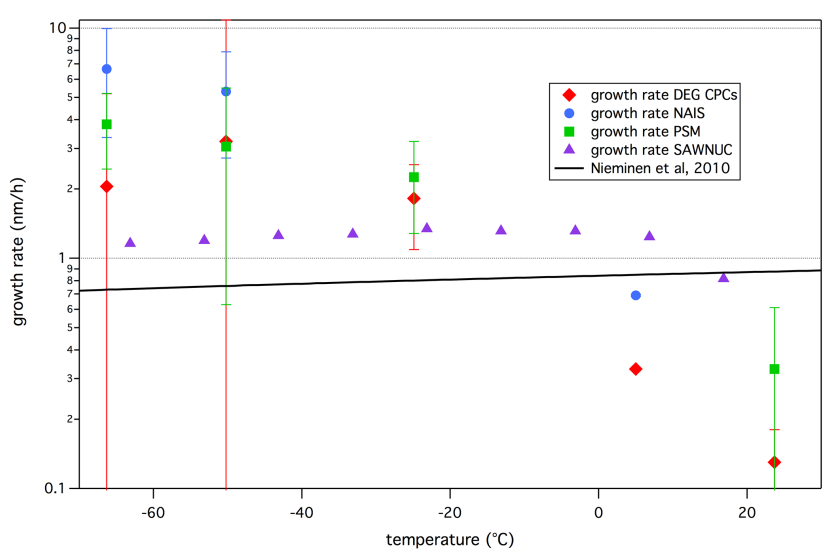

Figure 4. The growth rates normalized to a sulfuric acid concentration of $10^{7} \mathrm{~cm}^{-3}$ as a function of temperature. The GRs have been calculated using the laminar flow DEG-CPCs, the PSMs and the NAIS. Red symbols show the average growth rates at the given temperature determined from the DEG-CPCs, from the NAIS in blue and from the PSMs in green. The error bars show the standard deviation of the average. The black line shows the expected growth rates based on kinetic collisions of sulfuric acid molecules (Nieminen et al., 2010). The purple triangles show calculations using the SAWNUC model. The modelled results show a similar temperature trend, as here evaporation is taken into account.

growth rates. The growth rates are higher for lower temperatures and the growth rates decrease with increasing temperature, showing the same trend for all the instruments. The GRs calculated from the DEG-CPCs and the PSM agree within a factor of 1.2, whereas the GRs from the NAIS are about a factor of 2.2 higher compared to the DEG-CPCs at $208.15 \mathrm{~K}$. The higher GRs from the NAIS might be due to the fact that it was only measuring negatively charged particles, which are expected to be higher than neutral GRs (Laakso et al., 2003). They were calculated following the maximum concentration in each size bin of the NAIS (Kulmala et al., 2012). The growth rates due to kinetic collision-limited condensation of sulfuric acid show the opposite trend, i.e. a slight increase of the growth rate as function of temperature (Nieminen et al., 2010). This is very likely due to the effect that this calculation does not take evaporation from the particles into account.

\subsection{Theoretical calculation of growth rates}

The GR can be described as

$\mathrm{GR}=k_{\mathrm{c}} \Delta d_{p}$,

where $\Delta d_{p}$ is the change of diameter due to the condensing sulfuric acid and $k_{\mathrm{c}}$ is the condensation rate. The condensation rate and the change in diameter were determined for a particle of $2 \mathrm{~nm}$ with the SAWNUC model (Lovejoy et al., 2004). Equation (3) is only valid for situations without evaporation. Very small particles have higher evaporation rates than bigger particles due to the Kelvin effect (Mckenzie et al.,
1984). In fact particles below the critical diameter, if such a diameter exists, will mainly evaporate while particles bigger than the critical diameter will grow. In these calculations the evaporation effect on the growth rate is given by

$\mathrm{GR}=\left(k_{\mathrm{c}}-k_{\mathrm{e}}\right) \Delta d_{p}$,

where $k_{\mathrm{e}}$ is the evaporation rate as described by Lovejoy et al. (2004). This equation accounts for the evaporation of particles. The relative contribution of evaporation versus condensation is determined by the vapour pressure of the condensing species. At higher temperatures the growth rates were calculated for a sulfuric acid concentration of $7 \times 10^{8} \mathrm{~cm}^{-3}$, as at this temperature a significant background contamination of $\mathrm{NH}_{3}$ was present in the CLOUD chamber (Kirkby et al., 2011). $\mathrm{NH}_{3}$ can lower the saturation vapour pressure of sulfuric acid over these small aerosols, though the magnitude of this effect depends on the composition in gas and aerosol phase (Clegg et al., 2008). SAWNUC includes only aerosols containing $\mathrm{H}_{2} \mathrm{SO}_{4}$ and water in the calculation; nevertheless, the calculations give a good indication about the growth rate behaviour when evaporation can not be neglected. The results from those calculations compared to the experimental data are shown as the purple triangles in Fig. 4. The comparison with the data shows that the SAWNUC predictions show a similar temperature trend as the experimental data (i.e. smaller GR above $0^{\circ} \mathrm{C}$ ). This drop-off at higher temperatures remains unclear; nevertheless the higher GRs retrieved from the NAIS data compared to the SAWNUC model and to the GRs from the CPCs at the lower temperatures might be due to a charge enhancement (Laakso et al., 2003).

\section{Conclusions}

We investigated the performance of the DEG-based CPC under temperatures typical for the upper troposphere by performing a set of calibration measurements at temperatures between 248.15 and $208.15 \mathrm{~K}$. Here the CLOUD chamber was used as an aerosol particle source and a nano-DMA to size select the particles. As the total particle concentration was low, a single particle counter (PSM) was used as the reference instrument for the calibration measurements. The results show that there is a shift in the cut-off diameter of the CPC towards bigger sizes compared to the laboratory calibrations at room temperature. The cut-off sizes, relative to a PSM, were $2.5 \mathrm{~nm}$ for $207.25 \mathrm{~K}, 2.8 \mathrm{~nm}$ for $222.65 \mathrm{~K}$, $2.6 \mathrm{~nm}$ for $246.25 \mathrm{~K}$ and $1.4 \mathrm{~nm}$ relative to an electrometer for $298.15 \mathrm{~K}$ (room temperature) for the DEG-CPC 1 . As the maximum concentration of particles after the DMA was about $10 \mathrm{~cm}^{-3}$, the uncertainty in the cut-off diameters retrieved from those measurements is large. This means that the results show a clear shift in the cut-off diameters towards the bigger sizes, but the exact numbers for the cut-off diameters need to be treated carefully. Despite the big uncertainties in the measurement results, for the first time, a sub- $3 \mathrm{~nm}$ 
CPC has been calibrated under temperatures relevant to upper tropospheric. In addition, the calibration measurements were done using the same particle composition as for the nucleation measurements.

We used a method to analyze growth rates based on the difference in the cut-off sizes between two DEG-CPCs, using the results from the calibration measurements and compared the calculated growth rates with those derived from other instruments. To evaluate the validity of the results, the GRs have been compared to the growth rates determined from mixing type CPCs (PSMs) and an ion spectrometer (NAIS) at different temperatures. All the instruments show higher GRs for lower temperatures. The average values of the growth rates from the NAIS show somewhat higher values (factor of 2.2) compared to the GRs determined from the DEGCPCs. The growth rates derived from the PSM and DEGCPCs agree within a factor of 1.2. The growth rates show a similar temperature trend for all instruments and theoretical calculations. This indicates that growth rates at low temperatures might be underestimated. However, the CPCs detect both charged and neutral particles, whereas the NAIS measured charged particles. The GRs calculated from kinetically limited collision rates of sulfuric acid and water show the opposite temperature trend, but here evaporation is not taken into account. The SAWNUC (Lovejoy et al., 2004) model where evaporation is taken into account shows a similar temperature trend as the experimental data.

We have shown that when using CPCs at upper tropospheric temperatures, it must be taken into account that cutoff diameters might be shifted towards bigger sizes. This effect might be due to evaporation of the smallest particles. We ruled out the possibility of a change of the CPC performance by modelling the temperature profiles of the CPC inlet for 208.15 and $295.15 \mathrm{~K}$. The modelling results show the exact same resulting temperature at the beginning of the aerosol capillary. That suggests that the effect leading to the shift in the cut-off diameter is due to particle evaporation in the transition from the cold chamber into the warm CPC. Taking the cut-off shift (due to evaporation) into account, CPCs can still be reliably used as total particle counters, depending on the size distribution.

Acknowledgements. We would like to thank CERN for supporting CLOUD with important technical and financial resources, and for providing a particle beam from the CERN Proton Synchrotron. We also thank P. Carrie, L.-P. De Menezes, J. Dumollard, F. Josa, I. Krasin, R. Kristic, A. Laassiri, O. S. Maksumov, B. Marichy, H. Martinati, S. V. Mizin, R. Sitals, A. Wasem and M. Wilhelmsson for their important contributions to the experiment. We would like to thank Francesco Riccobono for helping with the setup of the calibration unit and we would also like to thank Jasper Kirkby for giving the opportunity to use the CLOUD chamber for the calibration measurements. This research has received funding from the EC Seventh Framework Programme (Marie Curie Initial Training Network "CLOUD-ITN" no. 215072, MC-ITN "CLOUD-TRAIN" no. 316662, ERC-Starting "MOCAPAF" grant no. 57360 and ERCAdvanced "ATMNUCLE" grant no. 227463), the German Federal Ministry of Education and Research (project nos. 01LK0902A and 01LK1222A), the Swiss National Science Foundation (project nos. 200020135307 and 206620 130527), the Academy of Finland (Center of Excellence project nos. 1118615, 135054, 133872, 251427, 139656, 139995, 137749, 141217, 141451), the Finnish Funding Agency for Technology and Innovation, the Väisälä Foundation, the Nessling Foundation, the Austrian Science Fund (FWF; project no. P19546 and L593), the Portuguese Foundation for Science and Technology (project no. CERN/FP/116387/2010), the Swedish Research Council, Veten-skapsradet (grant 2011-5120), the Presidium of the Russian Academy of Sciences and Russian Foundation for Basic Research (grants 08-02-91006-CERN and 12-02-91522-CERN) and the US National Science Foundation (grants AGS1136479 and CHE1012293).

Edited by: N. M. Donahue

\section{References}

Almeida, J., Schobesberger, S., Kürten, A., Ortega, I. K., Kupiainen, O., Praplan, A. P., Amorim, A., Bianchi, F., Breitenlechner, M., David, A., Dommen, J., Donahue, N. M., Downard, A., Dunne, E., Duplissy, J., Ehrhart, S., Flagan, R. C., Franchin, A., Roberto, G., Hakala, J., Hansel, A., Heinritzi, M., Jokinen, T., Junninen, H., Kajos, M. K., Keskinen, H., Kupc, A., 'en, T. K., Kvashin, A., Laaksonen, A., Lehtipalo, K., Leiminger, M., Leppä, J., Loukonen, V., Makhmutov, V., Mathot, S., McGrath, M., Nieminen, T., Olenius, T., Onnela, A., Petäjä, T., Riccobono, F., Riipinen, I., Rondo, L., Ruuskanen, T., Santos, F. D., Schallhart, S., Schnitzhofer, R., Seinfeld, J. H., Simon, M., Sipilä, M., Stozkhov, Y., Stratmann, F., Tomé, A., Tröstl, J., Tsagkogeorgas, G., Vaattovaara, P., Viisanen, Y., Virtanen, A., Vrtala, A., Wagner, P., Weingartner, E., Wex, H., Williamson, C., Wimmer, D., Ye, P., Yli-Juuti, T., Carslaw, K., Kulmala, M., Curtius, J., Baltensperger, U., Worsnop, D., Vehkamäki, H., and Kirkby, J.: Molecular understanding of amine-sulphuric acid particle nucleation in the atmosphere, Nature, 502, 359-363, 2013.

Ball, S. M., Hanson, D. R., Eisele, F. L., and McMurry, P. H.: Laboratory studies of particle nucleation: Initial results for $\mathrm{H}_{2} \mathrm{SO}_{4}$, $\mathrm{H}_{2} \mathrm{O}$ and $\mathrm{NH}_{3}$ vapors, J. Geophys. Res.-Atmospheres, 104, 23709-23718, 1999.

Clegg, S. L., Kleeman, M. J., Griffin, R. J., and Seinfeld, J. H.: Effects of uncertainties in the thermodynamic properties of aerosol components in an air quality model - Part 2: Predictions of the vapour pressures of organic compounds, Atmos. Chem. Phys., 8, 1087-1103, doi:10.5194/acp-8-1087-2008, 2008.

Crumeyrolle, S., Manninen, H. E., Sellegri, K., Roberts, G., Gomes, L., Kulmala, M., Weigel, R., Laj, P., and Schwarzenboeck, A.: New particle formation events measured on board the ATR-42 aircraft during the EUCAARI campaign, Atmos. Chem. Phys., 10, 6721-6735, doi:10.5194/acp-10-6721-2010, 2010.

Duplissy, J., Enghoff, M. B., Aplin, K. L., Arnold, F., Aufmhoff, H., Avngaard, M., Baltensperger, U., Bondo, T., Bingham, R., Carslaw, K., Curtius, J., David, A., Fastrup, B., Gagné, S., Hahn, F., Harrison, R. G., Kellett, B., Kirkby, J., Kulmala, M., Laakso, L., Laaksonen, A., Lillestol, E., Lockwood, M., Mäkelä, J., 
Makhmutov, V., Marsh, N. D., Nieminen, T., Onnela, A., Pedersen, E., Pedersen, J. O. P., Polny, J., Reichl, U., Seinfeld, J. H., Sipilä, M., Stozhkov, Y., Stratmann, F., Svensmark, H., Svensmark, J., Veenhof, R., Verheggen, B., Viisanen, Y., Wagner, P. E., Wehrle, G., Weingartner, E., Wex, H., Wilhelmsson, M., and Winkler, P. M.: Results from the CERN pilot CLOUD experiment, Atmos. Chem. Phys., 10, 1635-1647, doi:10.5194/acp-101635-2010, 2010.

Herrmann, W., Eichler, T., Bernardo, N., and Fernandez de la Mora, J.: Turbulent Transition Arises at Reynolds Number 35,000 in a Short Vienna Type DMA with a Large Laminarization Inlet, in: AAAR, annual conference, St Louis, Minnesota, USA, 2000.

Iida, K., Stolzenburg, M. R., and McMurry, P. H.: Effect of Working Fluid on Sub-2 nm Particle Detection with a Laminar Flow Ultrafine Condensation Particle Counter, Aerosol Sci. Technol., 43, 81-96, 2009.

Jiang, J., Attoui, M., Heim, M., Brunelli, N. A., McMurry, P. H., Kasper, G., Flagan, R. C., Giapis, K., and Mouret, G.: Transfer Functions and Penetrations of Five Differential Mobility Analyzers for Sub-2 nm Particle Classification, Aerosol Sci. Technol., 45, 480-492, 2011a.

Jiang, J., Chen, M., Kuang, C., Attoui, M., and McMurry, P. H.: Electrical Mobility Spectrometer Using a Diethylene Glycol Condensation Particle Counter for Measurement of Aerosol Size Distributions Down to $1 \mathrm{~nm}$, Aerosol Sci. Technol., 45, 510-521, $2011 b$.

Kangasluoma, J., Kuang, C., Wimmer, D., Rissanen, M. P., Lehtipalo, K., Ehn, M., Worsnop, D. R., Wang, J., Kulmala, M., and Petäjä, T.: Sub-3 nm particle size and composition dependent response of a nano-CPC battery, Atmos. Meas. Tech., 7, 689-700, doi:10.5194/amt-7-689-2014, 2014.

Kangasluoma, J., Franchin, A., Duplissy, J., Ahonen, L., Korhonen, F., Attoui, M., Mikkilä, J., Lehtipalo, K., Vanhanen, J., Kulmala, M., and Petäjä, T.: Operation of the Airmodus A11 nano Condensation Nucleus Counter at different inlet pressures, different operation temperatures and design of a new inlet system, Atmos. Meas. Tech. Discuss., submitted, 2015.

Kerminen, V.-M. and Kulmala, M.: Analytical formulae connecting the 'real' and the 'apparent' nucleation rate and the nuclei number Concentration for atmospheric nucleation events, J. Aerosol Sci., 33, 609-622, 2002.

Kirkby, J., Curtius, J., Almeida, J., Dunne, E., Duplissy, J., Ehrhart, S., Franchin, A., Gagné, S., Ickes, L., Kürten, A., Kupc, A., Metzger, A., Riccobono, F., Rondo, L., Schobesberger, S., Tsagkogeorgas, G., Wimmer, D., Amorim, A., Bianchi, F., Breitenlechner, M., David, A., Dommen, J., Downard, A., Ehn, M., Flagan, R. C., Haider, S., Hansel, A., Hauser, D., Jud, W., Junninen, H., Kreissl, F., Kvashin, A., Laaksonen, A., Lehtipalo, K., Lima, J., Lovejoy, E. R., Makhmutov, V., Mathot, S., Mikkilä, J., Minginette, P., Mogo, S., Tuomo, N., Onnela, A., Pereira, P., Petäjä, T., Schnitzhofer, R., Seinfeld, J. H., Sipilä, M., Stozhkov, Y., Stratmann, F., Tomé, A., Vanhanen, J., Viisanen, Y., Vrtala, A., Wagner, P. E., Hansueli, W., Weingartner, E., Wex, H., Winkler, P. M., Carslaw, K. S., Worsnop, D. R., Baltensperger, U., and Kulmala, M.: Role of sulphuric acid, ammonia and galactic cosmic rays in atmospheric aerosol nucleation, Nature, 476, 429-433, 2011.

Kuang, C., Chen, M., McMurry, P. H., and Wang, J.: Modification of Laminar Flow Ultrafine Condensation Particle Counters for the enhanced detection of $1 \mathrm{~nm}$ condensation nuclei, Aerosol Sci Technol., 46, 309-315, 2012a.

Kuang, C., Chen, M., Zhao, J., Smith, J., McMurry, P. H., and Wang, J.: Size and time-resolved growth rate measurements of 1 to $5 \mathrm{~nm}$ freshly formed atmospheric nuclei, Atmos. Chem. Phys., 12, 3573-3589, doi:10.5194/acp-12-3573-2012, 2012 b.

Kulmala, M., Mordas, G., Petäjä, T., Grönholm, T., Aalto, P. P., Vehkamäki, H., Hienola, A. I., Herrmann, E., Sipilä, M., Riipinen, I., Manninen, H. E., Hämeri, K., Stratmann, F., Bilde, M., Winkler, P. M., Birmili, W., and Wagner, P. E.: The condensation particle counter battery (CPCB): A new tool to investigate the activation properties of nanoparticles, J. Aerosol Sci., 38, 289-304, 2007.

Kulmala, M., Petäjä, T., Nieminen, T., Sipilä, M., Manninen, H. E., Lehtipalo, K., Maso, M. D., Aalto, P., Junninen, H., Paasonen, P., Riipinen, I., Lehtinen, K. E. J., Laaksonen, A., and Kerminen, V. M.: Measurement of the nucleation of atmospheric aerosol particles, Nature Protocols, 7, 1651-1667, 2012.

Kulmala, M., Kontkanen, J., Junninen, H., Lehtipalo, K., Manninen, H. E., Nieminen, T., Petäjä, T., Sipilä, M., Schobesberger, S., Rantala, P., Franchin, A., Jokinen, T., Järvinen, E., Äijälä, M., Kangasluoma, J., Hakala, J., Aalto, P. P., Paasonen, P., Mikkilä, J., Vanhanen, J., Aalto, J., Hakola, H., Makkonen, U., Ruuskanen, T., Mauldin, L. R., Duplissy, J., Vehkamäki, H., Bäck, J., Kortelainen, A., Riipinen, I., Kurtén, T., Johnston, M. V., Smith, J. N., Ehn, M., Mentel, T. F., Lehtinen, K. E. J., Laaksonen, A., Kerminen, V.-M., and Worsnop, D. R.: Direct Observations of Atmospheric Aerosol Nucleation, Science, 339, 943-946, 2013.

Kupc, A., Amorim, A., Curtius, J., Danielczok, A., Duplissy, J., Ehrhart, S., Walther, H., Ickes, L., Kirkby, J., Kürten, A., Lima, J. M., Mathot, S., Minginette, P., Onnela, A., Rondo, L., and Wagner, P. E.: A fibre-optic UV system for $\mathrm{H}_{2} \mathrm{SO}_{4}$ production in aerosol chambers causing minimal thermal effects, J. Aerosol Sci., 42, 532-543, 2011.

Kürten, A., Rondo, L., Ehrhart, S., and Curtius, J.: Performance of a corona ion source for measurement of sulfuric acid by chemical ionization mass spectrometry, Atmos. Meas. Tech., 4, 437-443, doi:10.5194/amt-4-437-2011, 2011.

Laakso, L., Kulmala, M., and Lehtinen, K. E. J.: Effect of condensation rate enhancement factor on 3-nm (diameter) particle formation in binary ion-induced and homogeneous nucleation, $\mathrm{J}$. Geophys. Res.-Atmos., 108, 4574, doi:10.1029/2003JD003432, 2003.

Lehtipalo, K., Leppä, J., Kontkanen, J., Kangasluoma, J., Franchin, A., Wimmer, D., Schobesberger, S., Junninen, H., Petäjä, T., Sipilä, M., Mikkilä, J., Vanhanen, J., Worsnop, D. R., and Kulmala, M.: Methods for determining particle size distribution and growth rates between 1-3 nm using the Particle Size Magnifier, Boreal Environ. Res., 19, 215-236, 2014.

Lovejoy, E. R., Curtius, J., and Froyd, K. D.: Atmospheric ioninduced nucleation of sulfuric acid and water, J. Geophys. Res.Atmos., 109, 204, doi:10.1029/2003JD004460, 2004.

Mäkelä, J., Riihela, M., Ukkonen, A., Jokinen, V., and Keskinen, J.: Comparison of mobility equivalent diameter with KelvinThomson diameter using ion mobility data, J. Chem. Phys., 105, 1562-1571, 1996.

Mckenzie, R. L., Agarwal, J. K., Pohl, F. G., Preining, O., Reischl, G., Szymanski, W., Wagner, P. E., Liu, B. Y. H., and Pui, D. Y. H.: Measurements of Kelvin-Equivalent Size Distributions of Well- 
Defined Aerosols with Particle Diameters Greater Than 13 Nm, Aerosol Sci. Technol., 3, 107-115, 1984.

McMurry, P. H.: The History of Condensation Nucleus Counters, Aerosol Sci. Technol., 33, 297-322, 2000.

Mirme, S. and Mirme, A.: The mathematical principles and design of the NAIS - a spectrometer for the measurement of cluster ion and nanometer aerosol size distributions, Atmos. Meas. Tech., 6, 1061-1071, doi:10.5194/amt-6-1061-2013, 2013.

Nieminen, T., Lehtinen, K. E. J., and Kulmala, M.: Sub-10 nm particle growth by vapor condensation - effects of vapor molecule size and particle thermal speed, Atmos. Chem. Phys., 10, 97739779, doi:10.5194/acp-10-9773-2010, 2010.

O'Dowd, C., Geever, M., and Hill, M. K.: New particle formation: Nucleation rates and spatial sscale in the coastal environment, Geophys. Res. Lett., 25, 1661-1664, doi:10.1029/98GL01005, 1998.

Riccobono, F., Rondo, L., Sipilä, M., Barmet, P., Curtius, J., Dommen, J., Ehn, M., Ehrhart, S., Kulmala, M., Kürten, A., Mikkilä, J., Paasonen, P., Petäjä, T., Weingartner, E., and Baltensperger, U.: Contribution of sulfuric acid and oxidized organic compounds to particle formation and growth, Atmos. Chem. Phys., 12, 9427-9439, doi:10.5194/acp-12-9427-2012, 2012.

Riipinen, I., Sihto, S.-L., Kulmala, M., Arnold, F., Dal Maso, M., Birmili, W., Saarnio, K., Teinilä, K., Kerminen, V.-M., Laaksonen, A., and Lehtinen, K. E. J.: Connections between atmospheric sulphuric acid and new particle formation during QUEST III-IV campaigns in Heidelberg and Hyytiälä, Atmos. Chem. Phys., 7, 1899-1914, doi:10.5194/acp-7-1899-2007, 2007.

Schobesberger, S., Junninen, H., Bianchi, F., Lönn, G., Ehn, M., Lehtipalo, K., Dommen, J., Ehrhart, S., Ortega, K. I., Franchin, A., Nieminen, T., Riccobono, F., Hutterli, M., Duplissy, J., Almeida, J., Amorim, A., Breitenlechner, M., Downard, A. J., Dunne, E. M., Flagan, R. C., Kajos, M., Kirkby, H. K. J., Kupc, A., Kürten, A., Kurtén, T., Laaksonen, A., Mathot, S., Onnela, A., Praplan, A. P., Rondo, L., Santos, F. D., Schallhart, S., Schnitzhofer, R., Sipilä, M., Tomé, A., Tsagkogeorgas, G., Vehkamäki, H., Wimmer, D., Baltensperger, U., Carslaw, K. S., Curtius, J., Hansel, A., Petäjä, T., Kulmala, M., Donahue, N. M., and Worsnop, D. R.: Molecular understanding of atmospheric particle formation from sulfuric acid and large oxidized organic molecules, Proc. Natl. Acad. Sci. USA, 110, 1722317228, 2013.
Sipilä, M., Lehtipalo, K., Attoui, M., Neitola, K., Petäjä, T., Aalto, P. P., O'Dowd, C. D., and Kulmala, M.: Laboratory Verification of PH-CPC's Ability to Monitor Atmospheric Sub-3 nm Clusters, Aerosol Sci. Technol., 43, 126-135, 2009.

Stolzenburg, M. R. and McMurry, P. H.: An Ultrafine Aerosol Condensation Nucleus Counter, Aerosol Sci. Technol., 14, 48-65, 1991.

Vanhanen, J., Mikkilä, J., Lehtipalo, K., Sipilä, M., Manninen, H. E., Siivola, E., Petäjä, T., and Kulmala, M.: Particle Size Magnifier for Nano-CN Detection, Aerosol Sci. Technol., 45, 533542, 2011.

Voigtländer, J., Duplissy, J., Rondo, L., Kürten, A., and Stratmann, F.: Numerical simulations of mixing conditions and aerosol dynamics in the CERN CLOUD chamber, Atmos. Chem. Phys., 12, 2205-2214, doi:10.5194/acp-12-2205-2012, 2012.

Wimmer, D., Lehtipalo, K., Franchin, A., Kangasluoma, J., Kreissl, F., Kürten, A., Kupc, A., Metzger, A., Mikkilä, J., Petäjä, T., Riccobono, F., Vanhanen, J., Kulmala, M., and Curtius, J.: Performance of diethylene glycol-based particle counters in the sub-3 nm size range, Atmos. Meas. Tech., 6, 1793-1804, doi:10.5194/amt-6-1793-2013, 2013. 